\title{
Recordando desde enero o ô mayo. Memoria y olvido en EI Salvador a partir del estudio estético de dos monumentos de la posguerra ${ }^{1}$
}

\author{
Eduardo Maciel \\ Universidad Centroamericana \\ "José Simeón Cañas", UCA
}

Resumen: En El Salvador la batalla por la memoria se libra en diferentes escenarios. Uno de ellos es la creación de lugares de memoria en el espacio público. A partir del estudio estético (especialmente desde algunos conceptos de Walter Benjamin) el presente ensayo se adentra a esta disputa analizando dos monumentos surgidos en la posguerra salvadoreña: el Monumento a la Reconciliación y el Monumento a La Memoria y la Verdad. Estos monumentos materializan dos propuestas heurísticas sobre la guerra que surgen de posiciones de poder dispares y contrarias. Para ilustrar esta diferencia de poder se usan dos alegorías temporales: enero representa a la heurística impulsada por las élites políticas de la posguerra (centrada en el discurso de la reconciliación, cuya figura son los Acuerdos de Paz); mientras que mayo simboliza aquella impulsada por las víctimas civiles (alegoría basada tanto en dos operaciones de tierra arrasada en mayo de 1980 y 1982, como en las acciones de resistencia contra la Ley de Reconciliación en mayo de 2019).

Palabras claves: Memoria, estética, Monumento a la Reconciliación, Monumento a la Memoria y la Verdad, batalla por la memoria, propuesta heurística, Walter Benjamin.

Abstract: In El Salvador, the battle over memory is fought on multiple plains, one of them the creation of places of memory in the public space. Drawing on the perspective of aesthetic studies (especially Walter Benjamin) this article explores the battle over memory as represented in two monuments that emerged 
from the Salvadoran postwar period: The Monument of Reconciliation and the Monument of Memory and Truth. These monuments materialize two heuristic proposals about war that arise from opposing positions of power. To illustrate this contrast in power, I use two temporal allegories: January represents the heuristic supported by the post-war political elites (centered on the discourse of reconciliation and whose symbol is the Peace Accords); whereas May represents the heuristic thrusted by the civilian victims (a temporal allegory based on two scorched-earth operations in May 1980 and 1982, as well as on the resistance actions against the Reconciliation Law in May 2019).

Keywords: Memory, aesthetics, Monument to the Reconciliation, Monument to the Memory and the Truth, battle over memory, heuristic proposal, Walter Benjamin.

\section{Introducción}

Como cualquier otro pueblo reciente de El Salvador. El 16 de que reconoce una historia común, el salvadoreño tiene un calendario propio, que le ayuda a identificar y a apropiarse del pasado compartido. En el periodo de posguerra, iniciativas provenientes del gobierno, partidos políticos y sectores de la sociedad civil, han ido incluyendo en sus trabajos de memoria algunas fechas de acontecimientos de la guerra civil importantes para cada sector, proponiéndolas como nuevos marcadores de la historia nacional. En este sentido propongo utilizar las alegorías ${ }^{2}$ de enero y mayo como claves de lectura que condensan las políticas de memoria de dos sectores fundamentales del periodo de posguerra.

La primera de estas metáforas es enero. Este es un mes altamente simbólico en la construcción de la cronología de la historia oficial enero de 1992, representantes del gobierno y del Frente Farabundo Martí para la Liberación Nacional (FMLN), firmaron los Acuerdos de Paz con los que pusieron fin a una guerra que provocó al menos 75,000 muertos y 10,000 desaparecidos. En la metáfora de enero convergen, bajo la insistencia en la reconciliación, las narrativas que fundamentan las políticas de memoria de distintos actores de la guerra, cuyo poder continuó y se fortaleció en el postconflicto. Es por ello que, a pesar de que la guerra terminara oficialmente sinvencedores nivencidos (Villalobos, 2000), quiero proponer, siguiendo a Walter Benjamin, que la narrativa desde enero representa la perspectiva de los vencedores, es decir, la de quienes tuvieron no solo el papel protagónico durante la guerra, sino, y sobre todo, en la posguerra. Me refiero con ello a los 
antiguos comandantes guerrilleros, a altos mandos militares y a importantes políticos de los partidos con presencia durante el conflicto que, una vez concluida la guerra, siguieron detentando el poder en el sector político que representan.

Ante esta tendencia, y con la intención de "cepillar la historia a contrapelo" (Benjamin, 2008, p. 23), es necesario rescatar un contrapunto a la memoria desde enero, que dé voz a las narrativas silenciadas por la política oficialista. En el caso de este artículo ese contrapunto es mayo. La alegoría de mayo tiene dos puntos de partida. El primero de ellos lo representan dos masacres contra campesinos desarmados efectuadas por el Ejército salvadoreño en ese mes: la masacre de Las Aradas (14 de mayo de 1980) y la Guinda de Mayo (27 de mayo a 9 de junio de 1982). Estas dos masacres no son hechos excepcionales. Ellas representan a un número mucho mayor de masacres cometidas durante el conflicto armado como parte de la estrategia militar contrainsurgente de quitarle el agua al pez ${ }^{3}$. Luego del fin de la guerra, numerosos trabajos antropológicos han sostenido que, tanto ex-combatientes como las bases civiles en los sectores rurales más afectados por la violencia durante el conflicto armado, encarnan los rostros del desengaño y el desencanto. Marcados por la pobreza, la represión, las guindas ${ }^{4}$ y la supervivencia en el pasado, muchos de ellos encarnan hoy el rostro de la desencanto a causa de la impunidad reinante en el posconflicto, así como por la precaria situación económica, la migración forzada, la pérdida de horizontes utópicos y los nuevos modos de violencia que afectan al país $^{5}$. El segundo punto de partida para esta metáfora temporal surge de la lucha de las víctimas del conflicto armado contra la aprobación de la Ley de Reconciliación en mayo de 2019. Esta propuesta de Ley fue rotundamente rechazada por agrupaciones de víctimas, sectores de la sociedad civil y organismos internacionales, pues, sin atender los reclamos de justicia y reparación de las víctimas, busca decretar una amnistía de facto (Salvioli, 2019). En este contexto, durante todo el mes de mayo se realizaron numerosas actividades de resistencia y denuncia contra la impunidad a lo largo y ancho del país. Una de ellas fue la presentación a la Asamblea Legislativa del proyecto de Ley de Reparación Integral de Víctimas del Conflicto Armado realizada por distintas agrupaciones de víctimas. Por todos estos motivos, se propone en este artículo la alegoría de mayo como imagen de las narrativas de memoria surgidas desde aquellos que no vencieron, pero que, pese a la gran desilusión vivida en la posguerra continúan realizando importantes trabajos de memoria en clave de resistencia. 
Ya que las políticas y los trabajos de memoria no se limitan a discursos, sino que forman parte de procesos que buscan materializarse en objetos, eventos, símbolos y lugares, la lectura estética de este fenómeno es muy pertinente y ha sido poco explorada en las investigaciones sobre memoria en El Salvador. De cara a ir llenando este vacío, el presente estudio busca explorar las huellas materiales de los trabajos y las políticas de memoria en dos experiencias del arte público en El Salvador de posguerra: el monumento a la Reconciliación y a la Memoria y la Verdad. Cabe destacar que para realizar esta exploración -y siguiendo la crítica de Benjamin (1989) en su ensayo sobre la obra de arte- este artículo se distancia de la noción clásica de estética ${ }^{6}$. En su lugar, busca rescatar una noción de estética que permita abarcar no solo el interés por el objeto-producto del arte, sino por todo el proceso creativo -esto es, su contexto cultural de producción-recepción y los procesos sociales y políticos que lo envuelven. Para ello, se ponen en diálogo algunas pistas de la estética benjaminiana -especialmente la imagen dialéctica y el montaje-, con experiencias recogidas en torno a la construcción de los dos monumentos estudiados, así como con algunas pistas teóricas acerca de la memoria y la historiografía.

\section{Marco teórico}

¿Quién construyó Tebas, la de las Siete Puertas?

En los libros aparecen los nombres de los reyes.

¿Arrastraron los reyes los bloques de piedra?

\section{Bertolt Brecht}

El fragmento del poema de Brecht citado arriba, introduce a la pregunta acerca del lugar desde el cual se escribe la historia; lo que relatan y silencian las narraciones sobre el pasado. En la misma línea del poema de Brecht, Walter Benjamin ha sugerido que la producción histórica es parcial y siempre se escribe desde la empatía con los vencedores. Para este autor las narrativas, documentos y archivos de los victoriosos, así como las realidades que ellos han impuesto sobre el terreno, conforman las fuentes de lo que se considera como verdad histórica. Siguiendo en esta misma línea de reflexión, pero haciendo más patente la dinámica del poder, el historiador haitiano Michel Trouillot (2017) sostiene que el interés del historiador debe estar en descubrir cómo funciona la historia. Con ello, basándose en Foucault, asevera que una de las tareas principales de esta disciplina es el sacar a la luz los entramados de poder que dan forma a las narraciones históricas. Para lograrlo, 
es necesario prestar tanta atención a los procesos y a las condiciones de la producción de narrativas, como a la fijación e imposición de los silencios (pp. 23 y 44-54).

Pensar el poder en las narrativas de la guerra salvadoreña y poner a hablar a los silencios, son los objetivos principales que guían el presente trabajo. Para lograr esta tarea de hacer elocuente los silencios, es necesario un cambio de posición y de enfoque, para ver el espacio -aunque sea intersticial e intermitente- en el que se hallan algunos resplandores del contrapoder frente a la narrativa dominante (Didi-Huberman, 2012, p. 31). Se trata de pesquisar las memorias subterráneas (Pollak, 2006) y su confrontación con el afán totalitario de las memorias nacionales. Posicionarse en los silencios de la narrativa oficial representa escuchar las memorias disidentes, esas contramemorias (Saadi y Abu-Lughot, 2017, p. 39) o memorias peligrosas (Metz, 2002) que cuestionan la continuidad $y$ actualidad del orden que hizo posible el horror y que desvelan una relación causal entre crímenes del pasado y la situación actual (p. 57).

Por otro lado, la reflexión en torno al fenómeno del poder y el silenciamiento de las narraciones de memoria, gira también alrededor del binomio visibilizacióninvisibilización. En este sentido, es importante traer a colación el concepto de lugar de memoria, presentado por Pierre Nora (2008, pp. 19-39). Estos lugares no son neutrales, sino que condensan material y visiblemente las propuestas heurísticas sobre el pasado (Sprenkels, 2017) 7 de una comunidad de memoria (Irwin, 1994) ${ }^{8}$. Como materialización de una heurística particular, los lugares de memoria crean nuevos repartos de lo sensible (Rancière, 2009), pasando a demarcar nuevas latitudes en los mapas sociales (Diez, 2014), y establecen nuevas relaciones de los sujetos con el espacio material. Con el estudio de los lugares de memoria:

"[...] lo que intentamos comprender no es solamente la multiplicidad de sentidos que diversos actores otorgan a espacios físicos en función de sus memorias, sino los procesos sociales y políticos a través de los cuales estos actores (o sus antecesores) inscribieron los sentidos en esos espacios [...]. Construir monumentos, marcar espacios, respetar y conservar ruinas, son procesos que se desarrollan en el tiempo, que implican luchas sociales, y que producen (o fracasan en producir) esta semantización de los espacios materiales" (Jelin y Langland, 2003, $p$. 3-4). 
En estrecha relación con los lugares de memoria se encuentra su vinculación con el arte en el espacio público. La emergencia de nuevos y diferentes actores sociales como impulsores de los procesos de memoria, ha generado en el mundo del arte de las últimas décadas una amalgama de prácticas denominadas arte político, basadas en el concepto de resistencia (Paz, 2016, p. 18). En esta línea, James Young (1993; 2000) introduce el término countermonument, para referirse a aquellas prácticas que adoptan una posición en contra de las presunciones del monumento tradicional, bajo la sospecha de que éste contiene una huella autoritaria marcada a través del contenido que transmite y que produce más olvido que recuerdo, al reemplazar el trabajo de la memoria colectiva por una forma material concreta. En consecuencia, Young propone monumentos radicales, algunos efímeros, otros que reclaman la participación de los observadores, como modo de luchar contra la invisibilidad.

Por último, se proponen los conceptos benjaminianos de imagen dialéctica ${ }^{9}$ y montaje ${ }^{10}$ como instrumentos estéticos para la lectura de los monumentos. La imagen dialéctica, como síntesis política de la historia, permite un encuentro súbito entre el ahora y lo sido, llevando la atención del presente a las injusticias desoídas del pasado -interrumpiendo con ello la complicidad entre historia e injusticia. La imagen dialéctica como resultado del montaje de los fragmentos desechados por la historia oficial- no es única, ni plena, ni total, sino siempre múltiple y parcial. Al igual que el montaje, es una imagen no-toda, y en ella se prepara una lógica de la experiencia (estéticohistórico-política) alternativa (García, 2017, pp. 101-102).

\section{Análisis estético de los monumentos}

\subsection{El Monumento a la Reconciliación: La memoria desde enero}

El 16 de enero de 1992 representantes del gobierno salvadoreño y de la guerrilla FMLN firmaron los Acuerdos de Paz en el castillo de Chapultepec, México. A través de este acontecimiento se llegó al tan anhelado alto al fuego de ambas partes en combate, luego de más de una década de guerra civil. Desde entonces, dicho acontecimiento se convirtió en un símbolo de los deseos de una nueva página en la historia de la nación centroamericana. En 2017, a 25 años de la firma, la siempre grande conmemoración de los Acuerdos de Paz tuvo símbolos especiales. El mayor de ellos fue la inauguración 
del recién construido monumento a la Reconciliación ${ }^{11}$.

Se trata de un monumento conmemorativo ubicado en un parque con el mismo nombre, al costado de la autopista Monseñor Romero. Su ideación y construcción fueron impulsadas por el Ministerio de Obras
Públicas, sin abrirse concurso público para su diseño. El monumento consta de tres figuras de bronce. Las figuras centrales, de 7 metros de altura, representan a un hombre y una mujer en uniforme militar que, abrazados y con palomas en las manos, caminan hacia adelante. Es la representación de los actores principales de

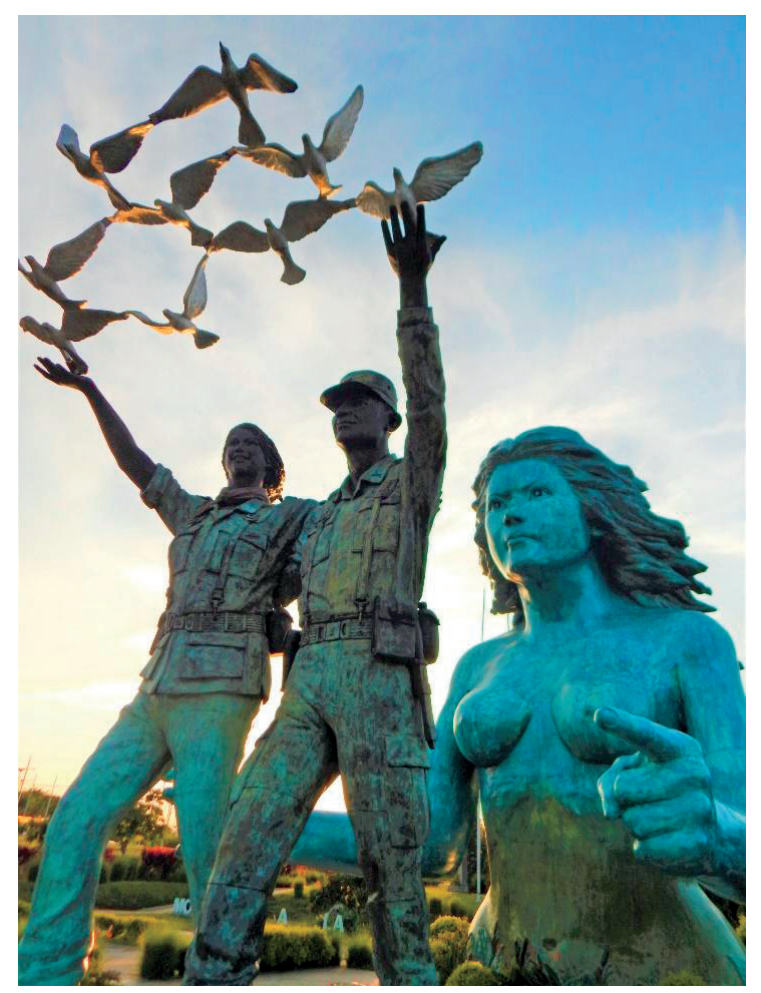

Imagen 1: Detalle de las figuras centrales del monumento de la Reconciliación.

Copyright Javiera Escobar Yametti.

la guerra: el ejército y la guerrilla. una mujer, desnuda, con los brazos Detrás de ellos se erige una enorme extendidos hacia adelante. Esta mujer, figura de 12 metros de altura, en símbolo de la Mater Civis, la patria o la la que se representa la figura de ciudadanía, lleva en la mano derecha 
un anillo, figura del pacto firmado en 1992, mientras que con la izquierda reprende a los hermanos que se enfrentaron. Las tres figuras centrales tienen como base la reproducción ampliada de las firmas "originales" de los firmantes de los Acuerdos.

Este complejo monumental es mucho más que un conjunto de figuras. Se presenta como una instantánea en la que se reúnen los elementos principales de la política de memoria-olvido de los distintos gobiernos de la posguerra. Para analizarlo hará falta prestar atención a lo que Didi-Huberman llama la política en las imágenes. Este autor francés entiende a las imágenes como una acción comunicativa que, aunque no posea una normatividad discursiva, conforma una manera paradigmática de narración de la historia. En el concepto de DidiHuberman hacen resonancia los Denkbilder de Benjamin, como esas imágenes de pensamiento, que siendo una imagen-fragmento del presente, remiten a la totalidad de un sistema ideológico, político y cultural (Tavani, 2010, p. 166).

A partir de estas pistas teóricas se puede pensar este monumento como una imagen dialéctica, que remite al menos a tres elementos de la propuesta heurística oficialista sobre la reconciliación que se analizan en los siguientes apartados, a saber: su representación de la historia; la elocuencia de los silencios y ausencias; y la relación entre reconciliación e impunidad.

\subsubsection{El Monumento a la Reconciliación y su representación del tiempo}

Para presentar el primer elemento de la propuesta heurística de los vencedores en el Monumento a la Reconciliación, se puede comenzar recordando la tesis IXsobre el concepto de historia de Walter Benjamin (2008). El monumento en su conjunto de figuras, parece ser abiertamente la contrapropuesta estética, histórica y política a la imagen del Angelus Novus, en la cual Benjamin funda su crítica al historicismo basado en el progreso. En aquel impresionante cuadro al óleo pintado en 1920 por el expresionista Paul Klee, Benjamin ve representado al ángel de la historia, quien se vuelve hacia atrás, de cara al pasado. Benjamin describe que lo impresionante de esa pintura es la expresión desorbitada de los ojos del ángel al dirigir la mirada hacia el pasado y descubrir en él las ruinas que deja a su paso el huracán del progreso. En la expresión de los ojos del ángel, Benjamin encuentra el sorpresivo descubrimiento del horror que ignora la historiografía basada en una imagen del tiempo como una línea continua y homogénea. Con aplomo y sin piedad, el huracán obliga 
al ángel a avanzar hacia adelante, sin la posibilidad de detenerse para socorrer a las víctimas de ese avance (p.24).

El conjunto de figuras centrales del monumento estudiado parece encarnar la visión del tiempo y de la historia que el autor berlinés crítica tan radicalmente en esa tesis. Las figuras del monumento insisten en un movimiento hacia el futuro. Por ello están literalmente de espaldas al pasado. Esa escenificación de la reconciliación da forma a una concepción del tiempo en la que el pasado se encuentra espaciotemporalmente atrás del tiempoahora (Jetztzeit).

Esta particular visión de reconciliación, se centra en el hecho singular de la firma que puso fin a la guerra y busca convertirlo en un hito histórico ${ }^{12}$, válido por y en sí mismo. Esta particular lectura de los Acuerdos como hito (o mito) que dio fin a un proceso pasado, refuerza la opción política de esta comunidad de memoria de negarse a tender lazos entre la desatención de las causas estructurales que llevaron al conflicto bélico en los ochenta y el conflictivo periodo de posguerra que está viviendo esta nación centroamericana. En este sentido, el monumento a la Reconciliación no solo le da la espalda al pasado, sino también al presente.
Para ampliar esta última afirmación, se hace necesario recurrir nuevamente a Benjamin. La reconciliación es escenificada en el complejo monumental como un evento englobante de la experiencia histórica pasada y actual. Esto recuerda la denuncia que Benjamin (1989) hiciera a inicios del fascismo, acerca de la estetización de la política. Con esta formulación, Benjamin se refirió a la búsqueda de mecanismos tecno-estéticos que produzcan la alienación de los sentidos y de la percepción de las masas, para que éstas no percibieran la destrucción que les era contemporánea como un horror (pp. 55-57). Esto es, un proceso de estetización que, como recuerda Susan Buck-Morss (1993), en lugar de afilar la percepción del sensorio corporal -a lo que hace referencia directa aisthesis, raíz etimológica de la palabra estética-, lo atrofia y adormece -funcionando como anestesia, anesthesis- ${ }^{13}$. La voluminosa presencia del monumento a la Reconciliación, funciona en este sentido como una fantasmagoría ${ }^{14}$, que busca engañar a los sentidos con los que se experimenta la cotidianidad de violencia en El Salvador. En su aplastante presencia - magnificada a través de técnicas de colorida iluminación nocturna-, el monumento parece buscar imponer una experiencia sensible ilusoria: la de vivir incuestionablemente en tiempos de paz. Parece buscar anestesiar la vivencia del posconflicto como otra experiencia de violencia 
fratricida - la cual genera en tiempos oficiales de paz más muerte, desapariciones y desplazamiento que en muchos periodos de la guerra ${ }^{15}$. En este sentido, el dedo amenazante de la figura de Civis, representación de la ciudadanía, alerta a los personajes centrales para que en un futuro no se vuelvan a enfrentar. Esta representación oculta y no da lugar a su experiencia sensible de vivir -y morir - en una guerra social (Gutiérrez, 2015) ${ }^{16}$ en el presente.

\subsubsection{La elocuencia de los silencios y las ausencias en el Monumento a la Reconciliación}

Para analizar este segundo elemento de la propuesta heurística de los vencedores, se hace necesario volver a pensar los ciclos de silencios en las narrativas históricas. Michel Trouillot (2017) afirma que una narrativa histórica es un documento del poder, no solo - ni tanto- por lo que dice, sino -sobre todo- por su capacidad de establecer determinados ciclos de silencios. Este poder no entra en la narrativa de una vez, sino en diferentes momentos y desde diferentes ángulos y mecanismos (p. 23). La construcción de símbolos, como el monumento estudiado, es uno de los mecanismos para fijar, desde el ángulo de la narrativa oficialista, un nuevo ciclo de silencios y ausencias. En el Monumento de la Reconciliación hay algunos elementos viejos y otros nuevos en lo referente a los silencios. Lo repetido es lo silenciado, lo ausente: las víctimas civiles del conflicto armado. Esta ausencia forma parte de una numerosa serie de silenciamientos e invisibilizaciones efectuados en el pasado. Tampoco es nuevo que en la narrativa oficialista, lo truncado, lo no llegado a ser y los sufrimientos continuados hasta el presente no tengan cabida, pues, su presencia deslegitimaría la fantasmagoría de la reconciliación. Lo que sí es nuevo en este ciclo es el instrumento que fija el silencio: un decreto presidencial para la reparación de las víctimas de graves violaciones de los derechos humanos durante el conflicto armado.

El Monumento a la Reconciliación surge del mandato de reparación moral y simbólica a las víctimas proveniente del decreto presidencial 204 del año 2013 (Presidencia de la República, 23.10.2013). Curiosamente, el monumento da cumplimiento al mandato de reparación a las víctimas, omitiéndolas. Como ya se dijo antes, el monumento celebra la reconciliación desde la perspectiva -y la imaginación exclusiva- de los actores oficiales de la guerra: el ejército, la guerrilla y los firmantes. Las víctimas civiles, quienes suman el 80 por ciento de las cerca de 75.000 víctimas mortales de la guerra, no tienen presencia, espacio, ni figura en el monumento. Ellos vuelven a ser ausentados -o si 
se quiere, vuelven a ser desaparecidos. Los silencios del monumento alertan que no basta con que la política gubernamental decrete y ejecute acciones de reparación moral, simbólica y económica a las víctimas del conflicto si ellas no son tomadas en cuenta como sujetos políticos y de memoria en el proceso que da forma y sentido a esa reparación ${ }^{17}$. En esta misma línea, Guadalupe Mejía, una de las representantes de las víctimas presentes en la inauguración del monumento, afirmó: "de nada servirá el monumento si no hay paz, justicia y verdad" (Autoridades inauguran, 15.01.2017).

\subsubsection{La narrativa de la reconciliación como sinónimo de impunidad: ¿un monumento al borrón y cuenta nueva?}

En tercer lugar, el Monumento a la Reconciliación aparece como una rúbrica de la política de olvido que sustenta la cultura de la impunidad en el país. La insistencia de las figuras en el mirar y caminar hacia adelante tiene una función ideológica patente: el llamado a superar el dolor, a pasar página, a la amnistía y al punto final. Este discurso sobre la reconciliación puede descubrirse desde el mismo inicio del periodo de posguerra. Más específicamente, en el rechazo abierto de los sectores implicados, al Informe realizado por la Comisión de la Verdad para El Salvador y la inmediata declaración de la Ley de Amnistía General más amplia en la historia del país. Desde ese momento, frases como borrón y cuenta nueva y el pasar página resumen la política oficialista de la memoria en el país.

A pesar de los ininterrumpidos reclamos de las organizaciones de Derechos Humanos y de las víctimas de la guerra, la posibilidad de la derogación de la Ley de Amnistía parecía, hasta hace muy poco, algo imposible. No fue hasta julio de 2016 que la Sala de lo Constitucional la declaró inconstitucional, abriendo con ello una posibilidad histórica para la reparación de las víctimas, el acceso a la justicia y la verdad. Pero las coincidentes declaraciones de representantes de la derecha, de altos militares y de la élite izquierdista, mostraron que el acceso a la justicia no sería tan fácil. Estos sectores se mostraron alarmados por el fallo y en bloque defendieron la derogada Ley. Las diferentes reacciones se podrían resumir en la declaración del entonces director de Protección Civil, Jorge Meléndez, para quien: "la Ley de Amnistía es una de las herramientas fundamentales para haber logrado los Acuerdos de Paz en el país" (Acevedo, 16.07.2016). En esta declaración se encuentra un ejemplo claro de lo que Ralph Sprenkels (2012) denomina memorias militantes, que son "propuestas de memorias públicas caracterizadas por la generación de lecturas históricas a conveniencia de 
intereses partidarios [y/o personales E.M.]" (p. 75). En sus declaraciones, Meléndez dio a entender que la Ley de Amnistía fue parte de la negociación en los Acuerdos de Paz, mientras que, en realidad, dichos acuerdos establecieron lo radicalmente opuesto: la creación de una Comisión de la Verdad para dar a conocer las graves violaciones contra los Derechos Humanos y superar la impunidad (El Salvador, 1992, p. 7).

En 2017, la Junta Directiva de la Asamblea Legislativa estableció una Comisión Ad Hoc para estudiar las implicaciones de la sentencia que invalidó la Ley de Amnistía General ${ }^{21}$ . En febrero de 2019, su presidente presentó una propuesta de Ley de Reconciliación Nacional que, "aunque enuncia dejar fuera de la amnistía a los crímenes de lesa humanidad y de guerra cometidos, contiene disposiciones que en la práctica derivan en una amnistía de facto "(Salvioli, 2019) ${ }^{22}$. En mayo de este año la comisión intentó acelerar el proceso de aprobación para asegurar que se efectúe antes del cambio de gobierno a realizarse en junio. Para ello contaba con el respaldo de las bancadas legislativas de ARENA y el FMLN (Bonner, 29.05.2019). Solo gracias al fuerte rechazo social,y la alerta internacional se logró frenar ese intento. Mayo fue nuevamente testigo de la resistencia de las víctimas. Desde sus denuncias se pudo volver a observar cómo desde la política que se hace desde enero, el término reconciliación cumple en realidad una función anestésica y de fantasmagoría - siendo sinónimo eufemístico de impunidad y olvido.

\subsection{El Monumento a la Memoria y la Verdad}

\section{"La Comisión recomienda: 1. La construcción de un monumento nacional en San Salvador con el nombre de todas las víctimas del conflicto, identificadas" Informe de la Comisión de la Verdad.}

A diferencia de los firmantes de los Acuerdos de Paz, cuyos nombres y firmas son reproducidos y amplificados en la base del monumento a la Reconciliación, las víctimas de la masacre de Las Aradas y de la Guinda de Mayo que en este artículo dan cuerpo a la contra-alegoría de mayo-, no tienen nombres, ni rostros, ni historias identificables. Se trata de cientos de personas procedentes de diferentes poblados de los departamentos de Chalatenango y Cabañas quienes, empujadas por los cercos militares en las operaciones de tierra arrasada, huían simultáneamente confluyendo en las orillas del río Sumpul -lugar donde muchas de ellas fueron asesinadas, y sus cuerpos abandonados desaparecieron arrastrados por el río o comidos por 
los animales. De muchas de ellas solo queda el recuerdo genérico de los testimonios de los sobrevivientes. Sólo de algunas pocas se pudieron recuperar sus nombres, los cuales fueron inscritos en el monumento a la Memoria y la Verdad, junto a los de otras miles de víctimas civiles del conflicto.

En 1997 un pequeño grupo de familiares de víctimas y de organizaciones de Derechos Humanos de la sociedad civil, ante la política oficialista de memoria de no reabrir las heridas del pasado, decide unirse para exigir el cumplimento de la primera de las recomendaciones de reparación realizada por el Informe de la Comisión de la Verdad: la creación de un monumento nacional que reconociera a las víctimas del conflicto. Luego de más de seis años de trabajo y de continuas luchas contra las políticas de olvido impuesto, el 6 de diciembre del 2003, se celebró la inauguración del monumento a la Memoria y la Verdad $^{23}$ en el Parque Cuscatlán ${ }^{24 .}$ Este monumento consta de un muro de 85 metros lineales cubierto por paneles de granito negro en los que se encuentran grabados en pequeñas letras blancas, organizados por año, los nombres de 194 masacres y los de 30.000 víctimas civiles del conflicto. Estas son listas incompletas ${ }^{25}$. En su primera etapa, el monumento contuvo 25.965 nombres. Posteriormente, en el 2008 se inauguraron nuevos paneles que sumaron otros 3.169 nombres de personas (Mendia Azkué, 2010). A esta segunda etapa también pertenece un mural de 17 metros de largo en el que se reconstruyen algunos de los eventos más significativos de la historia de violencia, resistencia y esperanza de El Salvador. Además, dos paneles, pertenecientes cada uno de ellos a una de las dos etapas de construcción del monumento, ofrecen una explicación acerca del sentido dado a este lugar de memoria.

Se proponen aquí dos pistas de la estética benjaminiana para conducir el estudio de este monumento. En primer lugar, el monumento a la Memoria y la Verdad puede ser pensado como una imagen dialéctica con varios niveles de significación. Como imagen dialéctica este monumento es la superficie de contacto en la que confluyen como síntesis - no solo histórica sino, sobre todo, política-, el tiempo-ahora y lo-sido. 


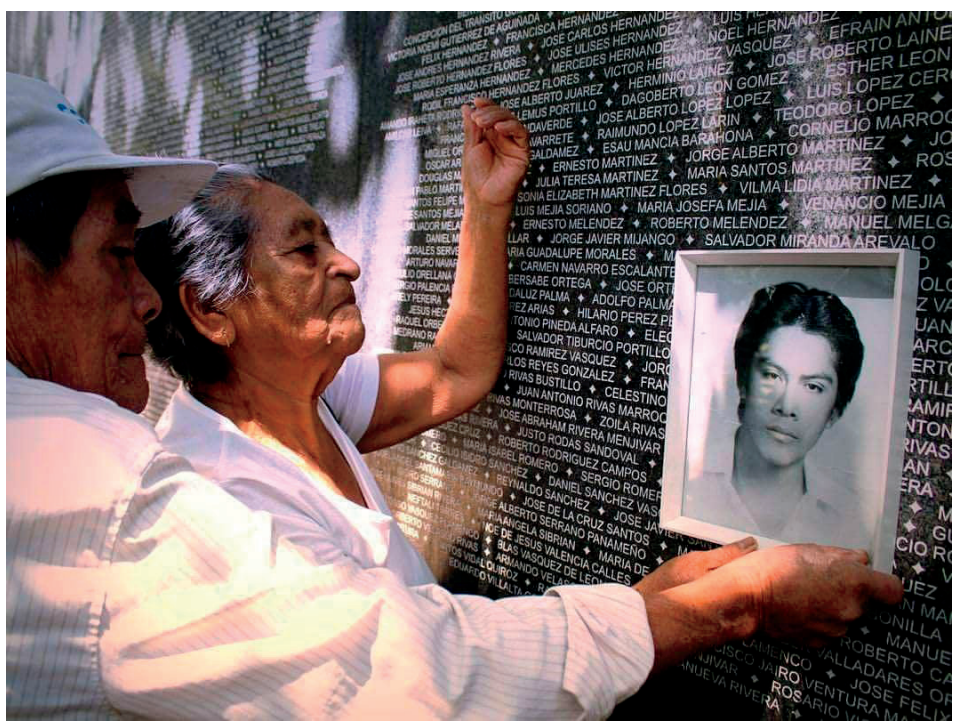

Imagen 2: Ancianos rinden homenaje a familiar desaparecido. Monumento a la Memoria y la Verdad, durante conmemoración del día de víctimas de desaparición forzada 30.08.2019. Copyright: Conabúsqueda.

En él (re)aparecen súbita $\mathrm{e}$ intermitentemente las historias de sufrimiento, resistencia y dignidad de las víctimas del conflicto armado. En su revelación, breve como un chispazo, de las ruinas históricas, las derrotas y lo no llegado a ser, la imagen dialéctica derrama su luz en el tiempo-ahora, descubriendo las pervivencias del pasado en él. La segunda pista de la estética benjaminiana que propongo es la del montaje. La praxis del montaje en Benjamin, hace referencia a la posibilidad de invención de formas no totales de articulación y composición a partir de los fragmentos que restan tras la ruina de la historia. Por ello, el montaje es el método para la creación de imágenes dialécticas. El montaje histórico sigue el mismo método del montaje estético: en primer lugar, se basa en la recuperación y resignificación de fragmentos descartados -en este caso, se trata de las narrativas desechadas en la construcción de la narración histórica oficialista. Para ello, es necesario sacar estos fragmentos de su contexto de insignificancia, aquel que los consideró como desechos, y resituarlos en un nuevo tejido de significación. A través de este rescate y reorganización de los desechos de la narrativa oficialista, el montaje ofrece una imagen nueva no solo del pasado, sino de sus tensiones y contradicciones vigentes aún en el presente (García, 2017, pp. 113-116). 


\subsubsection{Una experiencia del tiempo y la reconciliación en montaje}

En los elementos que conforman el monumento se pueden descubrir varios niveles de montaje. En sentido material, éste se compone de la confluencia de dos elementos principales: el muro de nombres y un mural - cada uno de ellos construidos a partir de otros fragmentos. El mural reúne los fragmentos que construyen la memoria de la violencia y la resistencia en el país desde la conquista española hasta los Acuerdos de Paz de 1992. Por su parte, 48 paneles individuales de granito negro, montados uno al lado de otro, conforman el muro de los nombres ${ }^{26}$. Estos paneles poseen diferentes contenidos que aportan distintos fragmentos de significación al muro. La mayoría de ellos contienen los nombres de las víctimas, por lo que cada uno de los paneles es también un montaje de aproximadamente 600 nombres. Existen también otros dos paneles con una lista inconclusa de 194 masacres contra la población civil; así como otros dos, pertenecientes cada uno de ellos a una de las dos etapas de construcción del monumento, con pequeños textos que narran su sentido. Por último, también se encuentra un panel vacío, que espera ser utilizado cuando se decrete Monumento Nacional (Hernández, 2015, p. 220).

A través del montaje que organiza su material, se accede a varios niveles de significación del monumento, presentándolo como un montaje de diferentes fragmentos de sentido. El primero de estos fragmentos hace referencia a la experiencia del tiempo. El monumento va listando, uno tras otro, los nombres de las víctimas mortales y de desaparición forzada de cada año del conflicto, desde la década de 1970 a 1991. Esta organización, que podría haber sido distinta - por ejemplo, alfabética como en el caso del muro de los nombres de Villa Grimaldi en Chile-, hace referencia a una experiencia estética de la historia y el tiempo, que es importante resaltar en las siguientes líneas.

Los lugares de memoria invitan al visitante a observar, a leer, a tocar, a ser parte de la instalación. En el monumento a la Memoria y la Verdad, por su extensión longitudinal, esta invitación a ser parte de la instalación está mediada por la urgencia a caminarlo. El recorrido sumerge al visitante en una primera narrativa del conflicto desde las víctimas de la represión. Esta narrativa presenta a la guerra como un evento extendido en el tiempo, donde cada elemento que da forma esa temporalidad es importante para entender al evento total. Un medio utilizado para comunicar la importancia de cada fragmento de esta historia es que los nombres de los miles de ciudadanos anónimos 
se ubican en igual nivel y tamaño que los de personajes renombrados como el poeta Roque Dalton o Monseñor Romero (Hernández, 2015, p. 219). Así, cada año, cada panel, cada nombre grabado, es un fragmento indispensable para la representación provisional de la magnitud de la herida social causada por el conflicto. Para completar esta primer imagen, es fundamental otorgar un espacio a la ausencia "de los nombres de miles de víctimas civiles que nunca llegaron a conocerse"zi. Con ello, y en radical oposición a la propuesta de las figuras del monumento a la Reconciliación, se reconoce la importancia de las víctimas anónimas para la construcción del evento histórico testimoniado.

Al mismo tiempo, la distinta cantidad de paneles de granito que ocupan los nombres las víctimas de cada año, ofrece al visitante una imagen casi gráfica de la dimensión de la violencia en los distintos periodos de la guerra. En este sentido, los nombres de las víctimas de 1980 a 1983, parecen no acabar. Su extensión longitudinal denuncia con simpleza y fuerza la especial crudeza de la guerra en su periodo inicial. Por otro lado, la inclusión de las víctimas civiles de la década de 1970 replantea la cronología de la violencia presentada por la Comisión de la Verdad y contribuye a visualizar la magnitud de la represión en el periodo de pre-guerra-especialmente el fenómeno de la desaparición, particularmente importante entre 1975-1979 (Hernández, 2015, pp. 210-214).

El final del muro de los nombres se encuentra el mural de la Memoria y la Verdad, realizado por el artista Mario Reyes ${ }^{28}$. En él se (re)presentan algunos de los acontecimientos de lucha, represión y violencia más emblemáticos de la historia salvadoreña. El mural posee una organización y movimiento que se desplaza en el sentido contrario al muro de los nombres. Mientras el muro se recorre desde la derecha hacia la izquierda, el mural de Reyes se recorre de izquierda a derecha. Esto quiere decir que, llegar al mural implica haber recorrido primero todo el muro de los nombres; y que luego de haber visitado el mural de la historia de El Salvador, el visitante debe volver a recorrer todo el muro. Esta disposición espacial del recorrido del monumento es otro de los medios que dan forma a la idea de la historia y la memoria desde mayo. En el primer movimiento, el reconocimiento de las víctimas de la guerra lleva al encuentro con todas las víctimas del pasado en el país, y a reconocer las raíces estructurales del conflicto. El segundo movimiento se presenta como una visualización panorámica de la línea histórica del país, cuyo eje estructurador no es la narrativa del poder, sino la de las víctimas. En este segundo recorrido, el visitante se mueve, metafóricamente, desde el pasado hacia el presente 
en la contemplación de la historia nacional como un ininterrumpido hecho de violencia y resistencia. Al terminar el segundo recorrido, el visitante se encuentra nuevamente en el presente, para interrumpir en él ese continuo de violencia. Esta experiencia de la historia mediada por el arte político, posibilita la superficie de contacto entre lo sido en el tiempo-ahora como tiempo y lugar para la transformación y la justicia.

En su extremo derecho el mural ofrece una elocuente alegoría de la paz. Se trata de un izote en flor que se va convirtiendo en pequeñas palomas blancas. Precisamente este es el punto en el que el mural confluye con el muro de los nombres. Gracias a una leve curvatura del monumento, el visitante puede percibir desde aquí todo el muro en su impresionante longitud. Ubicado frente a esta promesa de paz representada en el izote, el visitante tiene a derecha e izquierda,la enorme y continua historia de dolor-cuyas lógicas direccionales de representación confluyen en el izote. El lugar donde está posicionado el izote parece hacer referencia al significado que el sector social que representa la memoria desde mayo otorga a la paz y a la reconciliación. En primer lugar, la paz y reconciliación son presentados como un proceso en lucha y una promesa, no como un hecho. Estas se realizan solo de cara al pasado y a las víctimas. Esto es, una paz y reconciliación que se basan en el reconocimiento, la memoria y la dignificación de las víctimas. Solo desde esta posición se garantiza la no repetición del horror. Por otro lado, el visitante en su acto de observar es también observado a derecha e izquierda por esa historia de dolor. Las imágenes del mural y los miles de nombres del muro, invitan al visitante a tomar en serio la necesidad de una paz que no se construya de espaldas a ellas, pues, como diría Benjamin (2008), "tampoco los muertos estarán a salvo del enemigo, si éste vence. $Y$ este enemigo no ha cesado de vencer" (p. 22).

\subsubsection{El monumento como imagen dialéctica de la herida social. Entre la pérdida, el duelo y la esperanza del "nunca más"}

Los paneles de granito pulido reflejan tenuemente la imagen del observador que los recorre, ayudando a crear la sensación de autoreconocimiento en la observación de los nombres. A través de este lenguaje artístico el monumento a la Memoria y la Verdad conecta, como en una imagen dialéctica, al observador con la herida social de la que es parte. El concepto de herida social es utilizado por Doris Salcedo para designar a la herida colectiva que se forma en el entrecruce de procesos macrosociales y locales/personales. Salcedo sostiene que, si bien la pena de familiares y víctimas de este tipo de crímenes es profundamente 
íntima, la esencia de los eventos que la genera es política. La herida social es abierta en experiencias extremas, como la muerte violenta, la ausencia/imposibilidad de procesos comunitarios de duelo, llevando a la desestructuración de la confianza social (Riaño, 2005, pp. 95-96). En este sentido, el texto que da inicio a la segunda etapa del monumento identifica claramente al este lugar de memoria como un medio para trabajar socialmente esta herida:

"En diciembre del año 2003 se inauguró la primera etapa de grabación de 25.965 nombres de salvadoreños y salvadoreñas víctimas de violaciones a los derechos humanos, facilitando a miles de madres y familiares un espacio donde recordar y rendir homenaje a sus seres queridos" (2008).

Ante la herida social surgen narrativas de luto. Creadas por personas o colectivos que vivieron eventos catastróficos o regímenes de represión, estas narrativas problematizan la separación entre el dolor personal y el sentimiento de luto colectivo. Las narrativas de luto son una forma de acción social, que tiene como objetivo llamar la atención sobre lo que aconteció, rescatar la dignidad y el buen nombre de las personas muertas, expresar su indignación, evitar que acontezca de nuevo, encontrar responsables y hacer justicia (Arenas, 2015, p. 193-194). El texto grabado al inicio del monumento puede ser leído como una forma de estas narrativas:

"Este es un memorial para el encuentro, para nunca olvidarles, para honrar su memoria, devolverles la dignidad, no permitir que el horror se repita y sentar las bases para una cultura de paz y de verdadera reconciliación. Un espacio de esperanza, para seguir soñando y construyendo una sociedad más justa y de verdadera reconciliación" (2003).

La acción de grabar en piedra los nombres de las víctimas es también un aspecto importante a tener en cuenta a la hora de analizar el monumento. El nombre es un importante medio para recuperar la materialidad de la persona recordada y alimentar su memoria; éste le da identidad personal y construye un sentido sobre la persona ausente
(Hallam y Hockey, 2001). El nombre es una forma de tornar visibles a las víctimas e individualizar las pérdidas. Este proceso de individualización es fundamental para la dignificación de su memoria, pues, significa mostrar que tenían una historia: eran hijos, hermanos, padres, amigos, colegas de otras personas. En el caso aquí estudiado, el nombre grabado en el 
muro es buscado, acariciado, besado y adornado por sus familiares cuando visitan el monumento. No es raro que éstos lo resalten con color o recuadros de papel, que le dejen cartas y flores. El nombre es un importante vehículo de encuentro con el familiar perdido, especialmente en los casos de desaparición ${ }^{29}$.

Por otro lado, las acciones de resistencia en contextos de crímenes de lesa humanidad y de políticas de olvido, son un canal fundamental para la elaboración del duelo.Aunos metros del actual monumento se encuentra una placa, colocada a inicios de la década de 2000, luego que la alcaldía municipal de San Salvador otorgara un espacio en el Parque Cuscatlán para su construcción. La diminuta placa sentencia que en ese lugar será construido el monumento en cuestión. Una vez finalizada su construcción, esta placa no se retiró. Sigue estando ahí como una señal de los años de lucha que implicó la construcción del monumento. Una lucha y resistencia que, aún antes de su inauguración, ayudó a dignificar a las víctimas, sus familiares y la sociedad entera. En este sentido, Gloria Guzmán, una de las principales impulsoras del Comité Pro-Monumento, comenta la importancia del proceso de construcción del monumento como camino de sanación para sus participantes:

"El proceso les dio conciencia de ser víctimas, pero también de ser sujetas activas contra la impunidad. Los años de trabajo en la defensa de los derechos humanos, y de manera específica en esta experiencia que estamos analizando, han resituado a mujeres de distintas generaciones como sujetas políticas determinantes en la crítica al modelo de "paz social" y reconciliación que ha querido implantar el Estado" (Guzmán y Mendia Azkué, 2016, p. 54).

Una vez construido, el monumento posibilitó a los familiares de las víctimas, especialmente, los familiares de desaparecidos, el espacio para la realización de los rituales públicos del luto. Desde el año 2003 las celebraciones anuales del día de los muertos representan uno de los aspectos más interesantes de los usos del monumento como mediador del proceso de duelo. En esta importante festividad del mundo cultural centroamericano, el monumento se convierte en el campo santo faltante a muchas familias salvadoreñas, las que lo visten de flores, cartas y fotografías. El monumento es en esta celebración el escenario de variadas actividades culturales y de memoria que incluyen la música, la poesía, las celebraciones religiosas y la visita de muchos familiares de todos los puntos del país. Como lugar de dignificación de la memoria de los seres queridos perdidos en el conflicto armado, el monumento ayuda a los sobrevivientes y familiares a completar el tan postergado duelo. 
Todas estas experiencias mediadas por el monumento a la Memoria y la Verdad hacen pensarlo como un contramonumento (Young 1993; 2000). Sus presentaciones del tiempo y de la reconciliación no atrofian, sino que agudizan el sensorio corporal, facilitando la percepción de las pervivencias del pasado en el presente y dando sentido al trabajo de memoria como una lucha por una configuración nueva del presente.
Como experiencia contramonumental, el Monumento a la Memoria y la Verdad representa en un punto neurálgico de la cartografía de la memoria salvadoreña (Hernández, 2015), así como de la resistencia contra las políticas que pretenden sentenciar el olvido -ya sea a través del silenciamiento y la negación, como también de la monumentalización y las políticas de reparación.

\section{Conclusiones}

La posguerra salvadoreña, desde su inicio hasta la actualidad, se presenta como un tenso campo de batalla en el que se disputan distintas narrativas de significación sobre el pasado reciente. El cómo se van resolviendo esas tensiones sobre el pasado tiene grandes consecuencias en la organización política del presente. Si bien existen varias propuestas heurísticas sobre el sentido del pasado, en este artículo se hizo énfasis solo en dos. Este énfasis se debe a que en la alegoría de enero y mayo se ven representadas dos corrientes de trabajos de memoria que representan a los sectores más importantes y antagónicos de esta batalla: el de los vencedores - sean estos de derecha, militares o guerrilla-y el de los vencidos. La actualidad de esta lucha por el sentido del conflicto armado y su relación con la construcción política del presente ha sido especialmente testimoniada en mayo de éste año. En este sentido será muy importante seguir prestando atención al desarrollo de esta lucha por la memoria en el país a partir del primero de junio, fecha en que por primera vez luego de casi treinta años del fin de la guerra, el grupo de los vencedores del (post) conflicto deja de estar en la primera fila del poder político.

Por otro lado, se pudo ver que los monumentos producidos por cada uno de estos sectores, se presenta como una imagen dialéctica que revela la heurística particular de cada una de estas dos comunidades de memoria. Desde estos emplazamientos de memoria se puede percibir con cierto grado de inmediatez el contenido conceptual y práctico de sus diferentes ideas acerca de la historia, el tiempo y la reconciliación. Por su potencial de abarcar simultáneamente varios niveles de la experiencia de la 
posguerra, parece importante dar más lugar a los fenómenos relacionados con la estética, el arte y el espacio público en la investigación sobre la memoria en el país. Otras posibles investigaciones en esta línea se pueden hacer retomando los ricos elementos estéticos que acompañan las conmemoraciones comunitarias en torno a la memoria. A través de la música popular, la creación de murales, las exposiciones y el teatro juvenil, se expresan importantes elementos de la heurística grupal que no suelen ser suficientemente tomados en cuenta en las investigaciones.

\section{Referencias bibliográficas}

- Acevedo,X.(16.07.2016). Sala Constitucional concluye que Ley de Amnistía impedía la justicia a las víctimas. Gato Encerrado. Recuperado de: http:// elsalvadortrespuntocero.com/sala-constitucional-concluye-que-ley-deamnistia-impedia-la-justicia-a-las-victimas/

- Arenas, P. (2015). Luciérnagas de la memoria. Altares espontáneos y narrativas de luto en Medellín, Colombia. En Revista Interamericana Bibliotecología 38 (3), septiembre-diciembre, pp. 189-200.

- Autoridades Inauguran Monumento a la Reconciliación. El Diario de Hoy. (15.01.2017). Recuperado de: http://www.eldiariodehoy.com/ noticias/nacional/33185/autoridades-inauguran-monumento-a-lareconciliacion/

- Benjamin, W. (1989): La obra de arte en la época de su reproductibilidad técnica, en: Ibíd. Discursos interrumpidos I (pp. 15-57). Buenos Aires: Taurus, 1989.

- Benjamin, W. (2005). El libro de los pasajes. Madrid: Akal.

- Benjamin, W. (2006a). El origen del drama barroco alemán. En: Ibíd.: Obras I-1 (pp. 217-459). Madrid, Abada.

- Benjamin, W. (2006b). Dirección única. En: Ibíd: Obras IV-1. Madrid: Abada.

- Benjamin, W. (2007). Convoluto N: Teoría del conocimiento, teoría del progreso. En R. Tiedemann (Ed.). Walter Benjamin. Libro de los pasajes (pp. 459-490). Madrid: Akal.

- Benjamin, W. (2008). Tesis sobre el concepto de historia y otros fragmentos. Introducción y traducción de Bolívar Echeverría. México: Itaca-UNAM.

- Benjamin, W. (2012). El surrealismo. En A. Useros y C. Renduelles (Eds.). Escritos políticos (pp. 61-76). Madrid: Abada. 
- Binford, L. (2010). A Perfect Storm of Neglect and Failure: Postwar Capitalist Restoration in Northern Morazán, El Salvador. Journal of Peasant Studies, 37 (3), pp. 531-557. DOI: http://dx.doi.org/10.1080/03066150.20 10.494375

- Bonner, R. (29.05.2019). En El Salvador, la izquierda y la derecha se unen para pedir amnistía por los crímenes de guerra. New York Times. Recuperado de: https://www.nytimes.com/es/2019/05/29/el-salvadoramnistia-crimenes-de-guerra/

- Buck-Morss, S. (1993). Estética y anestésica: una revisión del ensayo de Walter Benjamin sobre la obra de arte. En La balsa de Medusa 25, pp. 55-98.

- Dickson-Gómez,J. (2002). The Sound of Barking Dogs: Violence and Terror among Salvadoran Families in the Post-war.Medical Anthropology Quarterly, 16 (4), pp. 415-438, DOI: http://dx.doi.org/10.1525/maq.2002.16.4.415

- Dickson-Gómez, J. (2004). ‘One Who Doesn't Know War, Doesn't Know Anything': The Problem of Comprehending Suffering in Postwar El Salvador. Anthropology and Humanism, 29 (2), pp. 145-158. DOI: http:// dx.doi.org/10.1525/ahu.2004.29.2.145.

- Didi-Huberman, G. (2012). Supervivencia de las luciérnagas. Madrid: Abada.

- Diez Tetamanti, J. M. (coord.). (2014). Hacia una geografía comunitaria: Abordajes desde cartografía social y sistemas de información geográfica. Comodoro Rivadavia: Universitaria de la Patagonia-EDUPA.

- El Salvador (1992). Acuerdos de Chapultepec. San Salvador: Secretaría Nacional de Comunicaciones.

- Flores, T. (1985). The anthropology of Aesthetics. Dialectical Anthropology, 10 (1/2), pp. 27-41.

- FMLN abrirá juicios de guerra. El Diario de Hoy (04.09.2008).

- García García, I. (2017).La comunidad en montaje: Georges Didi-Huberman y la política en las imágenes. En Aisthesis 61, julio, pp. 93-117.

- Gutiérrez,D.(04.02.2015).Guerra Social.Códigoyclave.Rebelión.Recuperado de: http://www.rebelion.org/mostrar.php?tipo=5 \&id=Dagoberto $\% 20$ Guti\%E9rrez\&inicio=0

- Guzmán G. y Mendia Azkué, I. (2013) Mujeres con memoria. Activistas del movimiento de derechos humanos en El Salvador. Bilbao: UPV-EHU.

- Guzmán G. y Mendia Azkué, I. (2016). Tejiendo la memoria desde abajo: el Monumento a la Verdad y la Memoria de El Salvador. En Revista Decisio 
52, enero-agosto, pp. 51-56 Recuperado de: http://www.crefal.edu.mx/ decisio/images/pdf/decisio_43_44/decisio-43-44-articulo-7.pdf

- Hallam, E. y Hockey, J. (2001). Death, memory and material cultured, New York: Berg.

- Hernández, G. (2015). Cartografía de la memoria: actores, lugares y prácticas en El Salvador de posguerra (1992-2015) (Tesis Doctoral). Universidad Autónoma de Madrid, Madrid.

- Irwin Zarecka, I. (1994). Frames of Remembrance: The Dynamics of Collective Memory. New Brunswick: Transaction Publishers.

- Jelin, E. y Langland, V. (2003). Las marcas territoriales como nexo entre pasado y presente. En Jelin, E y Langland, V. (Comps). Monumento, Memoriales y Marcas Territoriales (pp. 1-6). Madrid: Siglo XXI.

- Juániz Maya, J.R. (2017). A la paz, solo por la verdad. Informe del tribunal para la aplicación de la justicia restaurativa en El Salvador 2009-1016. San Salvador: UCA Editores.

- Juárez Ávila, J. (2011). Memoria e historia reciente en El Salvador: La necesidad de nuevos mitos en el presente salvadoreño. En E. Rey Tristán y P. Cagiao Vila: Conflicto, memoria y pasados traumáticos: El Salvador contemporáneo (pp. 275-284). Santiago de Compostela: Universidad de Santiago de Compostela.

- La Justicia de El Salvador declara inconstitucional la Ley de Amnistía. Diario el Mundo de Madrid (14.07.2016). Recuperado de: http://www.elmundo. es/internacional/2016/07/14/57875488e5fdeafe6f8b4695.html

- La Ley de amnistía en el plano electoral. Co-Latino (05.09.2008).

- Mendia Azkue, I. (2010). Gloria Guzmán Orellana. En L. Alonso y M. Mesa. Semblanzas. 1325 mujeres tejiendo la paz. Madrid: CEIPAZ. Recuperado de: http://www.1325mujerestejiendolapaz.org/sem_gloria.html

- Metz, J. B. (2002). Dios y Tiempo. Nueva Teología Política. Madrid: Trotta.

- Moodie, E. (2010). El Salvador in the Aftermath of Peace. Crime, Uncertainty and Transition to Democracy. Philadelphia: University of Pennsylvania Press.

- Morales, D. y Navas, Z. (2006). Masacres. Trazos de la historia salvadoreña contados por las víctimas. San Salvador: CPDH Madeleine Lagadec.

- Naciones Unidas (1993). De la locura a la esperanza. La guerra de 12 años en El Salvador. Informe de la Comisión de la Verdad para El Salvador (19921993). San Salvador-Nueva York: ONU. 
- Nora, P. (2008). Pierre Nora en Les Lieux de mémoire. Montevideo: Trilce.

- Paz Fernández, N. (2016). Memoria histórica y arte público. Revista: On the Waterfront, 47. Barcelona: Universidad de Barcelona-PAUDO. Recuperado de: http://revistes.ub.edu/index.php/waterfront/article/view/18676.

- Presidencia de la Nación (26.10.2013). Decreto Ejecutivo $n^{\circ} 204$. Programa de reparaciones a las víctimas de graves violaciones a los derechos humanos ocurridas en el contexto del conflicto armado interno. Recuperado de: http://www.jurisprudencia.gob.sv/DocumentosBove da/D/2/2010-019/2013/10/A300B.PDF

- Pollak, M. (2006). Memoria, olvido, silencio: la producción social de identidades frente a situaciones límite. Buenos Aires: Ediciones al Margen.

- Rancière, J. (2009). El reparto de lo sensible. Estética y política. Santiago: LOM.

- Riaño, P. (2005). Encuentros artísticos con el dolor, las memorias y las violencias. Iconos. Revista de Ciencias Sociales 21, enero, pp. 91-104.

- Saadi, A. H. y Abu-Lughod, L. (Eds). (2017). Nakba. Palestina, 1948, y los reclamos de la memoria. Buenos Aires: Canaan.

- Salvioli, F. (2019). Observaciones Preliminares sobre la Visita Oficial a El Salvador por el Relator Especial sobre la promoción de la verdad, la reparación y las garantías de no repetición, Señor Fabián Salvioli, 23 de abril a 3 de mayo de 2019. Recuperado de: https://www.ohchr.org/SP/ NewsEvents/Pages/DisplayNews.aspx?NewsID=24557\&LangID=S

- Santos M. [Productor]. (2014). Las voces en el muro [Documental]. San Salvador: Audiovisuales UCA. Recuperado de: https://www.youtube.com/ watch?v=Nr9KalJZS-I

- Silber, I.C. (2018). Cotidianidad revolucionaria. Género, violencia y desencanto en la posguerra salvadoreña. San Salvador: UCA Editores.

- Sprenkels, R. (2011). La memoria militante. Historia y política en la posguerra salvadoreña. En E. Rey Tristán y P. Cagiao Vila (coords.): Conflicto, memoria y pasados traumáticos: El Salvador contemporáneo (pp. 255-273). Santiago de Compostela: Universidad de Santiago de Compostela.

- Sprenkels, R. (2012). La guerra como controversia: una reflexión sobre las secuelas políticas del informe de la Comisión de la Verdad para El Salvador. En Identidades 2(4), pp. 68-89.

- Sprenkels, R. (2017). El trabajo de memoria en Centroamérica: cinco propuestas heurísticas en torno a las guerras de El Salvador, Guatemala 
y Nicaragua. En Revista de Historia 76, julio-diciembre, pp. 13-46. DOI: http://dx.doi.org/10.15359/rh.76.1

- Tavani, E. (2010). L'esperienza estetica come esperienza di'immagini: Walter Benjamin e Theodor W. Adorno. En Revista Aisthesis II (2), pp. 163-179. Recuperado de: http://www.fupress.net/index.php/aisthesis/ article/view/11018/10390

- Trouillot, M. (2017). Silenciando el pasado. El poder y la producción de la historia. Granada: COMARES.

- Villalobos,J. (2000). Sin vencedores ni vencidos: pacificación y reconciliación en El Salvador. San Salvador: Instituto para un nuevo El Salvador INELSA.

- Young, J. (1993). The texture of memory. Holocaust Memorials and Meaning. New Haven: Yale University Press.

- Young, J. (2000). At Memory 's Edge. New Heaven: Yale University Press, 2000.

- Zeeuw, J. de (2010). Sons of war: parties and party systems in post-war El Salvador and Cambodia. En Democratization 17 (6), pp. 1176-1201. DOI: http://dx.doi.org/10.1080/13510347.2010.520549.

- Zinecker, H. (2011). Más muertos que en la guerra. El enigma de la violencia en Centroamérica. San Salvador: Friedrich-Ebert-Stiftung.

\section{Notas}

1. Poco tiempo después de presentar este artículo se publicó un ensayo de Rachel Hatcher en el que se analizan ambos monumentos desde una perspectiva similar a la de este trabajo. A diferencia del de Hatcher, el presente trabajo se construye estrictamente desde la estética y la historiografía benjaminiana. Ver: Rachel Hatcher (2019): The Victims and Violence of Civil War: Presences and Absences in El Salvador's Monumental Narratives of Reconciliation, DOI:10.1080 /00043389.2019.1611193.

2. Se adopta aquí el concepto benjaminiano de alegoría, presentado en El origen del drama barroco alemán (Benjamin (2006a). En esa obra, el autor berlinés contrapone la alegoría al símbolo, especialmente en la diferente experiencia de la tempora- lidad que cada una de estas nociones conllevan. Mientras el símbolo se instala en el tiempo eterno de la idea, subsumiendo con ello lo efímero en un canon temporal fijo y estable; la alegoría rehabilita la historicidad mostrando el curso dialéctico de la historia, poniendo de relieve la trama móvil y política de la historia (pp. 375-408). Es en este sentido que "enero" y "mayo" se entienden como alegorías de la confrontación dialéctica de dos propuestas heurísticas de memoria desarrolladas durante el periodo de posguerra en El Salvador.

3. En esta formulación, el agua representa el sustento civil en las zonas rojas del conflicto; el pez, es la guerrilla. Con el objetivo de acabar con la guerrilla, los operativos de tierra arrasada buscaron 
destruir toda la vida en esas regiones: ganado, sembradíos, cosechas y poblaciones enteras. En la actualidad existe bastante literatura que, a partir de los testimonios de los sobrevivientes civiles de estos operativos militares, presentan las características de la estrategia militar de quitarle el agua al pez. Como ejemplo se puede consultar: D. Morales y Z. Navas (2006). Masacres. Trazos de la historia salvadoreña contados por las víctimas. San Salvador: CPDH Madeleine Lagadec; J. R. Juániz Maya (2017), A la paz, solo por la verdad. Informe del tribunal para la aplicación de la justicia restaurativa en El Salvador 2009-1016. San Salvador: UCA Editores.

4. El término guinda se utiliza en el sector rural salvadoreño para designar la huida rápida y espontánea de poblaciones enteras ante la represión de los operativos militares en la zona.

5. Ver: I.C. Silber (2018). Cotidianidad revolucionaria. Género, violencia y desencanto en la posguerra salvadoreña. San Salvador: UCA Editores; L. Binford (2010). A Perfect Storm of Neglect and Failure: Postwar Capitalist Restoration in Northern Morazán, El Salvador. Journal of Peasant Studies, Vol 37 (núm. 3), pp. 531-557. DOI: http://dx.doi.org/10.1080/030661 50.2010.494375.; E. Moodie (2010). El Salvador in the Aftermath of Peace. Crime, Uncertainty and Transition to Democracy. Philadelphia: University of Pennsylvania Press; J. Dickson-Gómez (2002). The Sound of Barking Dogs: Violence and Terror among Salvadoran Families in the Post-war. Medical Anthropology Quarterly, Vol 16, (núm. 4), pp. 415-438, DOI: $\quad$ http://dx.doi.org/10.1525/ maq.2002.16.4.415; J. Dickson-Gómez (2004). 'One Who Doesn't Know War, Doesn't Know Anything': The Problem of Comprehending Suffering in Postwar El Salvador. Anthropology and Humanism, Vol 29 (núm. 2), pp. 145-158. DOI: http:// dx.doi.org/10.1525/ahu.2004.29.2.145.
6. Se entiende aquí como noción clásica de estética, a aquellas corrientes provenientes de Baumgarten y de la tercera crítica de Kant, donde la atención se centra en la elitista e individual actitud de contemplación desinteresada de una belleza universal en un objeto de arte, aislado éste de su función y su contexto histórico-social. Ver T. Flores (1985). The anthropology of Aesthetics. Dialectical Anthropology, Vol. 10 (núm. 1/2), pp. 27-41.

7. Según Ralph Sprenkels (2017), la heurística es, en esencia, una herramienta de simplificación cognitiva del mundo circundante que cohesiona a una comunidad de memoria en torno a una versión de la historia que compite vis-a-vis con otras versiones por la resonancia pública. A través de su particular marco de interpretación del pasado, las comunidades de memoria simplifican las tareas de interpretar, juzgar, y tomar decisiones a partir del uso selectivo de información y conocimiento (pp. 19-21).

8. Iwona Irwin (1994) utiliza el término comunidades de memoria para destacar cómo miembros de una sociedad pueden dividirse en diferentes grupos sociales que comparten una interpretación del pasado que se distingue de o incluso contradice la de los otros grupos.

9. Para adentrarse a la propuesta del término de imagen dialéctica consultar: W. Benjamin (2007). Convoluto N: Teoría del conocimiento, teoría del progreso. En R. Tiedemann (Ed.). Walter Benjamin. Libro de los pasajes (pp. 459-490). Madrid: Akal; W. Benjamin (2012). El surrealismo. En A. Useros y C. Renduelles (Eds.). Escritos políticos (pp. 61-76). Madrid: Abada; W. Benjamin (2008). Sobre el concepto de historia.

10. El método estético-político del montaje es analizado e implementado en los escritos de Benjamin, especialmente a partir del ciclo inaugurado con Calle de dirección única; y es imprescindible para adentrarse al inconcluso proyecto 
de Los pasajes. Ver: W. Benjamin (2006b) Dirección única. En: Obras IV-1. Madrid: Abada; W. Benjamin (2005). El libro de los pasajes. Madrid: Akal.

11. El monumento a la Reconciliación de 2017 vino a reemplazar a otro monumento que, hasta entonces, daba forma a la heurística oficialista de la guerra. Se trata del monumento de La Paz, inaugurado en 1994 en ocasión de los Juegos Deportivos Centroamericanos y construido, en parte, a base a la fundición de casquillos de bala y fusiles pertenecientes a ambos bandos. En sus primeros años, el monumento funcionó como lugar de conmemoración de los Acuerdos de Paz.

12. Esta auto-(re)presentación busca propagar un cierto culto a los firmantes, a sus dificultades, buenos sentimientos, capacidad de diálogo, la cual, según Jorge Juárez (2011), va de la mano con la necesidad de crear nuevos mitos fundacionales y próceres nacionales.

13. Susan Buck-Morss (1993) basa su clásico comentario sobre el ensayo de La obra de arte en la época de su reproductibilidad técnica en el juego de palabras estética-anestésica. Desde la relación entre estética-anestésica-fascismo estudia la problemática de la estatización de la política.

14. Las fantasmagorías son una tecno-estética, que proporcionan percepciones lo suficientemente «reales», pero con una función social compensatoria. La meta es la manipulación del sistema sinestésico mediante el control de los estímulos medioambientales. Tiene como efecto anestesiar el organismo, no entumeciéndolo, sino inundando los sentidos. Estas simulaciones sensoriales alteran la conciencia casi como una droga, y sus efectos se experimentan colectivamente, no de modo individual. En consecuencia, y de modo distinto a como sucede con las drogas, la fantasmagoría adquiere una posición de hecho objetivo. Busca convertirse en la norma social. La adic- ción sensorial a una realidad compensatoria, se convierte en medio de control social (Bucks-Morss, 1993, pp. 75-81).

15. Heindrun Zinecker (2011) estudia el enigma de la violencia en Centroamérica, desde la observación de que los postconflictos en la región están marcados por una violencia mayor a muchos de los periodos de las guerras civiles y conflictos armados vividos en el istmo en la segunda mitad del siglo XX. La experiencia cotidiana de la muerte y la violencia estructural es resumida en una frase de Hellen Moodie, citada por Sprenkels en uno de sus trabajos: "la paz es peor que la guerra”. Al respecto, comenta Sprenkels: "Si bien no hay monumentos que proclamen que "la paz es peor que la guerra" [...] ideas similares se expresan en otros productos culturales y mnemónicos, por ejemplo, en las artes plásticas o en la literatura centroamericana" (Sprenkels, 2017, p. 32). Las novelas de Castellanos Moya o la exposición de Mayra Barrera, "100 días en la república de la muerte" pueden ser un ejemplo de esta afirmación.

16. Según Dagoberto Gutiérrez (2015), al finalizar la guerra civil, se abre un momento histórico de ausencia de guerra y de paz. Este particular momento fue usado para construir una nueva economía de capitalismo neoliberal y privatizadora, un nuevo Estado sometido al mercado, un mercado dueño del poder total y organizador de la nueva sociedad. Este contexto genera nuevas formas de violencia, como la pandilleril y la de la Policía Nacional Civil. Las elevadas tasas de homicidios diarios, junto a la falta de oportunidades para superar la pobreza, empujan diariamente a cientos de jóvenes a la migración ilegal, sobre todo hacia los Estados Unidos, dejando el campo vacío y aumentando el desencanto hacia formas de organización social. Cfr. D. Gutiérrez (04.02.2015). Guerra Social. Código y clave. Rebelión. Recuperado de: http://www.rebelion.org/ 
mostrar.php?tipo=5\&id=Dagoberto $\% 20$ Guti\%E9rrez\&inicio=0

17. En el último decenio, los gobiernos del FMLN adoptaron una serie de medidas legislativas, judiciales y de política pública que consiguieron en parte reimpulsar el proceso de justicia transicional salvadoreño. Sin embargo, las organizaciones de la sociedad civil han criticado los obstáculos burocráticos y la insuficiencia de recursos para desarrollar estas medidas, lo que en muchos casos las vuelven inoperables (Salvioli, 2019).

18. El Informe de la Comisión de la Verdad surgió de un mandato de los mismos Acuerdos de Paz, según el cual se debían investigar los graves hechos de violencia ocurridos desde 1980 cuya huella sobre la sociedad reclama con mayor urgencia el conocimiento público de la verdad (Naciones Unidas, 1993, p. 9). Para su elaboración se escucharon 22.000 testimonios. Entre ellos se eligieron 33 casos considerados ejemplares para la elaboración de la publicación masiva del informe.

19. El mismo Mauricio Funes, primer presidente del FMLN, durante su campaña electoral del 2008 declaró, que, de ser electo, no derogaría la controversial Ley. Ver: La Ley de amnistía en el plano electoral. Co-Latino (05.09.2008); FMLN abrirá juicios de guerra. El Diario de Hoy (04.09.2008).

20. Luego de la declaración de inconstitucionalidad de la ley de amnistía general, se han abierto distintas causas penales, derivadas en su mayoría de las quejas presentadas por las víctimas. Casos emblemáticos como los de la masacre de El Mozote, la masacre de El Calabozo, las ejecuciones de los jesuitas, y la ejecución del Arzobispo Romero fueron reabiertos sin registrar ningún avance procesal. De estos litigios, frenados durante los años de impunidad, solamente presenta avances judiciales el caso de la masacre de El Mozote (Salvioli, 2019).
21. Desde un principio, esta Comisión fue fuertemente criticada en razón de: i) su mandato que incluye la función de interpretar las implicaciones de la sentencia, lo cual no puede ni debe ser una prerrogativa del poder legislativo; ii) su composición, ya que cuatro de sus [cinco] miembros presentan un conflicto de intereses, al haber sido protagonistas del conflicto armado y dos de ellos están mencionados en el informe de la Comisión de la Verdad, y (iii) su método de trabajo, sin suficiente transparencia, y especialmente la falta de participación efectiva -más allá de lo formal- de las víctimas y las organizaciones sociales, cuya voz debe ser privilegiada por sobre la de los actores del conflicto (Salvioli, 2019).

22. A saber: aplicación de la prescripción, plazos que restringen las investigaciones penales, eliminación de la pena de encarcelamiento, otorgamiento de beneficios de reducción de pena sin establecer condicionamientos tales como el reconocimiento de la responsabilidad, la colaboración con las investigaciones, y el suministro de la verdad (Salvioli 2019).

23. A la hora de analizar este monumento es importante tomar en cuenta que mientras el monumento a la Reconciliación se construyó a través del Ministerio de Obras Públicas (MOP), en un proceso cerrado, es decir, sin convocatoria abierta de artistas, ni espacios que permitan la participación ciudadana en la reflexión e ideación del mismo; el monumento a la Memoria y la Verdad se fue creando a través de un difícil y rico proceso de participación colectiva y de base -así como en constante necesidad de reivindicación de la iniciativa frente a gobiernos que abiertamente dificultaban y bloqueaban el avance del proceso y negaban los permisos para obtener los espacios. Sin financiamiento gubernamental, se llevó a cabo a través de donaciones particulares y de instituciones solidarias (Guzmán y Azkué, 2013, pp. 81-88). 
24. Georgina Hernández (2015) resalta la importancia simbólica del lugar de emplazamiento del monumento. El Parque Cuscatlán es el área verde más grande y antigua de la capital salvadoreña. Éste fue escenario, durante los años setenta, de concentraciones multitudinarias, de marchas de organizaciones sindicales y de madres de desaparecidos que denunciaban los actos arbitrarios de violencia. A través del monumento, la ausencia es traída al centro mismo de la capital, desde donde muchas veces salían las órdenes para cometer los actos de violaciones (p. 218).

25. En el año 2001, antes de comenzar el grabado de nombres en los paneles de granito, el Comité Pro-Monumento publicó un suplemento en el Diario Co-Latino con la lista de nombres que iban a ser grabados. El fin de este suplemento llamado "Nombres para no olvidar" era brindar la oportunidad para que las víctimas se acercaran a completar el listado agregando los nombres aún no incluidos (Guzmán y Azkué, 2013, p. 84).

26. En su estilo y materiales, el monumento a la Memoria y la Verdad posee una gran similitud al memorial de los veteranos de Vietnam, de Washington. La diferencia fundamental entre ambos es que, mientras el Vietnam Veterans Memorial es un homenaje a miembros de la fuerza armada que murieron en servicio en esa guerra, y por ello un monumento legitimador de la acción bélica, el monumento a la Memoria y la Verdad es un lugar de memoria de víctimas civiles - lo cual lo hace cercano a otros muchos memoriales en América Latina -especialmente al monumento a las Víctimas del Terrorismo de Estado, de Argentina.

27. Fragmento del texto del panel dedicado a las víctimas anónimas, perteneciente a la primera etapa de construcción del monumento y ubicado al inicio del mismo.

28. En comunicación personal con Ralph Sprenkels del 02.07.2019, quien desde la Asociación Pro-Búsqueda participó en el grupo gestor del monumento, comentó que el mural de Reyes fue realizado en base a un diseño de Camilo Minero, quien ya estaba demasiado frágil de salud para iniciar el mural y falleció poco después.

29. Un film documental sobre el monumento a la Memoria y la Verdad, titulado "Las voces en el muro" (Santos, 2014) ayuda a percibir la importancia de la individualización de las víctimas para su dignificación. Entre sonidos del bullicio de una multitud hablante, la imagen en la pantalla se va acercando al muro hasta centrarse en uno de los nombres y resaltarlo. A partir del nombre individualizado se reconstruyen tres de las 30.000 historias presentes en el monumento. Cada una de estas tres vidas representan a uno de los casos de violaciones a los Derechos Humanos presentes en el muro: desaparición forzada, masacres y niñez desaparecida. A través de recursos audiovisuales, el documental logra comunicar la importancia del monumento como instrumento de sanación de la herida social. El documental ayuda a percibir al monumento como un lugar donde confluyen mucho más que nombres. A través de fotografías, objetos personales y el testimonio propio o de familiares, los nombres del muro toman cuerpo, adquieren rostros y ganan voz. Así los nombres dejan de ser letras grabadas en piedra, para pasar a percibirse como treinta mil historias individuales y colectivas de dolor y pérdida, que merecen duelo y resistencia. 